\title{
Molecular Characterization of Diarrheagenic Bacteria Isolated from Stool of Under-five Children in Dar Es Salaam. Tanzania
}

\author{
Benjamin Enos Ngoso \\ Ifakara Health Institute, P. O. Box 53, Ifakara. Tanzania
}

Tel: 255-713-863-943

Dr. Lucy Andrew Namkinga (Corresponding author)

Department of Molecular Biology and Biotechnology

College of Natural and Applied Sciences, P. O. Box 35179, University of Dar Es Salaam

Dar Es Salaam. Tanzania

Tel: 255-784-772-552Ｅ-mail: odulajalucy@yahoo.com

\author{
Dr. Gamba Nkwengulila \\ Department of Zoology, College of Natural and Applied Sciences \\ University of Dar Es Salaam, Dar Es Salaam. Tanzania \\ Tel: 255-784-887-166Ｅ-mail: gamba@udsm.ac.tz
}

Received: October 12, 2015 Accepted: November 3, 2015

doi:10.5296/jbls.v7i1.8929 URL: http://dx.doi.org/10.5296/jbls.v7i1.8929

\begin{abstract}
Diarrhea is a daily public health song in developing countries like Tanzania. The causative agents are theoretically known almost to everybody. However, the eradication of this killer disease for the under-fives is an enigma. This study aimed to provide update advantages of molecular diagnostic versus conventional methods as regards to acute diarrhea, and to determine bacterial causes of diarrhea among children aging five years and below in Dar Es Salaam, Tanzania, using multiplex PCR technique.

Samples were collected from the under-fives from district hospitals in Dar Es Salaam city between June 2010 and February 2014. This included children admitted due to acute and/ or
\end{abstract}


chronic diarrhea. A total of 3600 stool samples were analyzed, of which 1800 samples were from diarrhea cases and 1800 samples from normal control cases. About 1080 (60\%) of the patients recruited were aged less than 3 years and 983 (54.6\%) were males. Diarrheagenic bacteria were isolated and identified using conventional stool cultures then were characterized by mPCR.

Pathogenic bacteria were detected in $67.7 \%$ of the cases and in $20 \%$ of the controls. The pathogenic bacteria most strongly associated with diarrhea disease were diarrheagenic Escherichia coli (21.6\% of cases, $6 \%$ of controls), Shigella spp. (16.1\% of cases, $5 \%$ of controls) and Salmonellae, (10.6\% of cases, 3\% of controls. The pathogenic bacteria were mostly from children aging from 24 months and above.

Diarrheagenic bacteria play an important role in relation to childhood diarrhea aging from two years and above. Proper diagnostic methods, prevention and control through fostering good hygiene and sanitation to water and food should be emphasized especially to oral-faecal age.

Keywords: Childhood diarrhea, Diarrheagenic bacteria, Developing country

\section{Introduction}

Diarrheal diseases are a leading cause for morbidity and mortality for under-five children in developing countries, whereby in Africa, the under-five mortality is approximately $42 \%$, and in Tanzania diarrhea is the fourth cause of morbidity and fifth cause of mortality (Kosek, et al., 2003, Parashar, et al., 2003, Bryce et al., 2005, WHO, 2005, MoHWF 2008, Boschi-Pinto et al., 2008, Kotloff et al., 2013, Mashoto et al., 2014). The etiologic agents of diarrhea are known, that includes viruses (e.g. rotaviruses, enteric adenoviruses), bacteria (e.g., Salmonella, Shigella, Campylobacter, enterotoxigenic Escherichia coli, cytotoxigenic Clostridium difficile), and parasites (e.g. Entamoeba histolytica, Giardia lamblia, Cryptosporidium parvum) are the leading causes (Presterl et al., 2003, Rappelli et al., 2005, Park et al., 2006, WHO 2013, Ngosso et al., 2015). Other precipitating factors of diarrhea includes; irritable bowel syndrome intolerance to some foods components (e.g. lactic acid), reaction to medicines (e.g. antibiotics or antacids containing magnesium) and some conditions such as malnutrition etc.

Diarrhea is very common in areas of poor hygiene, lack of clean and safe drinking water, overcrowding and the trend towards infants bottle-feeding instead of breastfeeding. Breastfeeding reduces risks of diarrhea for babies (Gascon et al., 2000, WHO, 2005, UNICEF, 2008). Consumption of contaminated food, water or direct fecal contamination through fingers is the major cause of transmission of entero-pathogens prevailing in the rural settings. (WHO, 2013, WHO, 2014). The under-five children are more prone to diarrheal infections because this age group is known as oral-faecal age group, which means they pick everything they see and eat or swallow (Kosek, et al., 2003, WHO, 2007, Moyo, et al., 2011).

Relatively few studies have been carried out in Dar Es Salaam using molecular characterization for the agents of diarrhea, one study dealt with identification of diarrheagenic E. coli only (Moyo et al., 2007), others dealt with the prevalence of 
entero-pathogenic viruses only (Moyo et al., 2007), rotaviruses (Mhalu et al., 1998) and parasitic protozoa causes (Ngosso et al., 2015).

Epidemiological data on pathogens causing diarrhea from developing countries generally does not include E. coli as causative organism. This is because there is no approved testing methods available for the identification e.g. of the six known diarrheagenic E. coli strains (Reither et al., 2007).

The only method available in most developing nations for the identification of bacterial diarrheal pathogens is conventional bacterial culture from stool. This method requires a minimum of 48-72 hours for identification of bacteria, which always leads to a delay of treatment and poor prognosis of patient. The method also is unable to discriminate between strains e.g. the pathogenic and nonpathogenic strains of e.g. E. coli. Furthermore, no commercially available methods exist to differentiate among the six different E. coli patho-types associated with diarrhea, including entero-hemorrhagic E. coli (EHEC), entero-pathogenic E. coli (EPEC), entero-aggregative E. coli (EAEC), entero-toxigenic $E$. coli (ETEC), diffuse adherent E. coli (DAEC), and entero-invasive E. coli (EIEC).

Studies done in Dar Es Salaam and elsewhere (Mwambete and Joseph, 2010, Ghasemi, et al., 2013), on mothers' knowledge on predisposing factors of childhood diarrhea was directly associated with educational level. Diarrhea episodes for infants were perceived wrongly as a normal growth stage.

In most of the developing countries health services are often not accessible by poor people especially women. The major obstacles are smaller per capita health expenditure, long distances to health facilities, inadequate and unaffordable transport systems, poor quality of care especially proper diagnosis of cases, and poor governance and accountability mechanisms (R\&AWG, 2002, REPOA, 2003, National Bureau of Statistics Tanzania, 2002, Jafari et al., 2009, WHO, 2015).

The causative agents of diarrhea are known to change from time to time and hence the need for continuous monitoring. Simple and effective diagnostic tool such as molecular techniques serves to provide timely and accurate diagnosis and improves management of diarrhea for under-five children in developing countries.

To this end, this study characterized the spectrum of isolated bacteria from diarrheagenic stools of the under-five children using conventional and modern methods. Multiplex PCR technique was used to reach the proper diagnosis of the causes of diarrhea and to encourage the use of such methods at least at the district hospital levels so as to reach for specific diagnoses and proper treatment for children.

\section{Ethical Clearance}

Ethical and research clearance-IHRDC/ IRB/ No. A29 was obtained from the Ifakara Health Institute Research and Ethical Committee. Permission to conduct two studies (parasitic diarrheal infection and bacterial diarrheal infections) was sought from the respective hospital authorities. An informed verbal consent was obtained from parents/ guardians of the children 
before enrolment into the study.

\section{Materials and Methods}

The study was carried out at the district hospitals in Dar Es Salaam city between June 2010 and February 2014. The eligibility criteria included children at the age of five years and below hospitalized due to acute and /or chronic diarrhea.

A total of 3600 stool samples were analyzed, of which 1800 samples were from diarrhea cases and out of which 60\% were aged less than 3 years and 983 (54.6\%) were males. Again, out of 1800 specimens collected, 1350 were from acute diarrhea cases and 450 from chronic diarrhea cases. Samples were collected using wide-mouthed sterile plastic bottles by trained nurses and clinicians. Specimens were transported in Cary-Blair transport media (Difco laboratories, USA) to Muhimbili National Hospital central pathology laboratory and their duplicates were preserved for PCR analysis.

\section{Bacteriological Procedures Stool Cultures}

Faecal samples were inoculated on diverse culture media; blood agar, Salmonella-Shigella-agar, Mac-Conkey agar, cefsulodin-Irgasan agar, novobiocin, and thiosulphate-citrate-bile salts-sucrose (TCBS) agars. Cultures were incubated at $37{ }^{\circ} \mathrm{C}$ for 24 to 48 hours. For Salmonella enrichment, samples were inoculated in Selenite-F broth at $37{ }^{\circ} \mathrm{C}$ for 18 hours and sub-cultured on Salmonella-Shigella agar. The Campylobacter blood-free medium was used to isolate Campylobacter species and plates were incubated for 48 hours at $42^{\circ} \mathrm{C}$ under micro-aerophilic conditions. All plates were examined, and the colonies suspected of corresponding to entero-pathogenic bacteria were identified by API test and PCR tests.

\section{Analytical profiling index (API-20E) test}

API 20E (Bio-Merieux- SA, France) commercial kit, is a biochemical test, used to speciate family Enterobacteriaceae and other non fastidious Gram negative rods basing on sugar fermentation and assimilation tests.

Each micro-tube containing dehydrated substrate was inoculated with a saline bacterial suspension prepared following Mc-Farland standard 0.5 (as per manufacturer's directions). Some of the tubes were completely filled with the suspension (tests CIT, VP and GEL) whereas other tubes were topped off with mineral oil for anaerobic reactions to take place (tests $\mathrm{ADH}, \mathrm{LDC}, \mathrm{ODC}, \mathrm{H}_{2} \mathrm{~S}, \mathrm{URE}$ ). The API test strips were incubated in a small, plastic humidity chamber for $18-24$ hours at $37^{\circ} \mathrm{C}$. This allowed living bacteria to produce metabolites and wastes as part of being a functioning cell whereby reagents in the cupules tested the presence of products of bacterial metabolism specific to certain kinds of bacteria. After incubation, each tube (an individual test) was assessed for a specific color change indicating the presence of a metabolic reaction that gave the microbial identity. Some of the cupules contents contained end products which were identified using additional reagents.

Interpretation of the 20 reactions test results, in addition to the oxidase reaction (which was 
done separately) were converted to a seven-digit code. Then the codes were entered into a computer software (ApiWeb TM) that gave the names of bacteria species associated with each seven-digit string of numbers.

\section{Bacterial DNA extraction for PCR assays}

\section{Guanidinium thiocyanate DNA extraction method without alpha casein}

An adaptation of the protocol reported by Boom et al. (1990) was used for this study. Stool suspension was vortexed, homogenized and centrifuged at 13000 revolutions per minute for 5 minutes, the pellet was used for DNA extraction and the supernatant discarded. The pellet was suspended in $700 \mu 1$ lysis buffer containing; $5.25 \mathrm{M}$ guanidium thiocyanate, $0.1 \mathrm{M}$ tris hydrochloride, 0.2 M EDTA and 1.3\% (weight/vol.) Triton X-100 and incubated at $70{ }^{\circ} \mathrm{C}$ for $10 \mathrm{~min}$. A volume of $250 \mu \mathrm{l} 100 \%$ (vol/vol) ethanol was added to this mixture and further incubated at $56{ }^{\circ} \mathrm{C}$ for 10 minutes. The celite solution $(50 \mu \mathrm{l})$ was added and incubated at room temperature for $10 \mathrm{~min}$ (with occasional mixing of the mixture). A sterile spin column, prepared according to the method published by Borodina et al, (2003), was placed into a sterile $2 \mathrm{ml}$ microfuge tube and the mixture loaded into the column. The mixture was loaded by adding approximately $500 \mu \mathrm{l}$ of the lysis mixture into the column followed by centrifugation at 13000 revolutions per minute for 30 seconds to separate the buffer from the celite. This step was repeated twice until all of the lysis mixture was loaded into the column. The column was washed twice with $400 \mu \mathrm{l}$ wash buffer $(5.25 \mathrm{M}$ guanidium thiocyanate and $0.1 \mathrm{M}$ tris hydrochloride) and twice with $400 \mu \mathrm{l}$ of $70 \%$ (vol./vol.) ethanol solution, separating the liquid and solid phase each time by centrifugation at $13000 \mathrm{r} / \mathrm{min}$ for $30 \mathrm{~seconds}$, followed by a 2 minutes centrifugation step at 13,000 revolutions per minute to ensure that all the ethanol was removed from the column. Columns were transferred into clean sterile $1.5 \mathrm{ml}$ microfuge tubes and $100 \mu$ l elution buffer (AE buffer, Qiagen) was added to the columns and incubated for 2 minutes at $56{ }^{\circ} \mathrm{C}$. DNA was eluted from the columns by centrifugation for 2 minutes at 13000 revolutions per minute after which the columns were discarded. DNA containing AE buffer was collected into the $1.5 \mathrm{ml}$ microfuge tube. A negative control was included by performing the DNA extraction methods with only the DNA extraction reagents. A positive control was prepared by extracting DNA from $1.5 \mathrm{ml}$ culture of the bacteria.

\section{DNA amplification of target genes}

Thirteen gene targets from E. coli, Salmonella spp., Shigella spp., Yersinia enterocolitica, Vibrio cholerae, and Campylobacter jejuni diarrhegenic organisms were amplified using oligo-nucleotide primer pairs listed in One micro liter of crude DNA preparation mixed with $24 \mu \mathrm{l}$ of a pre-made mix containing primers at a $0.2 \mu \mathrm{M}$ final concentration and Platinum Blue PCR Super-Mix polymerase (Invitrogen, Carlsbad, CA). The combination of 5 to 6 pairs of primers per primer group, and designated as; M1, M2, and M3, are described in Table 1. The PCR program used for amplification consisted of 2 min at $94{ }^{\circ} \mathrm{C}$ of denaturing temperature, followed by 40 cycles of $30 \mathrm{~s}$ at $92{ }^{\circ} \mathrm{C}$ of denaturing temperature, $30 \mathrm{~s}$ at $59{ }^{\circ} \mathrm{C}$ of annealing temperature, and $30 \mathrm{~s}$ at $72{ }^{\circ} \mathrm{C}$ of extension temperature. At the end of the 40 cycles, a 5 min extension at $72{ }^{\circ} \mathrm{C}$ was used before samples were ready for analysis. 


\section{Gel electrophoresis and visualization of DNA}

DNA was analyzed in a horizontal agarose slab gel (2.5\% (weight/vol)) containing ethidium bromide $(0.5 \mu \mathrm{g} / \mathrm{m} \ell)$ in TAE buffer ( $40 \mathrm{mM}$ tris-acetate; $2 \mathrm{mM}$ EDTA, $\mathrm{pH} 8.3)$. The agarose gel was electrophoresed for 1 hour at 100 Volts. The DNA was visualized with UV light. The relative sizes of the DNA fragments were estimated by comparing their electrophoretic mobility with 100 bp markers (Fermentas O' Gene Ruler DNA ladder; Canada).

\section{Results}

Among the bacterial isolates, DEC were found in $21.6 \%$ of cases and $7 \%$ of the controls while Shigella spp. (16.1\% of cases, $5 \%$ of controls) (Table 1). DEC was the commonest among children of 6-11 month old age group, accounting for $63.6 \%$ of all cases in this age group; $75 \%$ of all DEC episodes occurred during the first year of life. Shigella spp. was the commonest among those in 12-23 months age group and 24-60 months age groups, accounting for $33.7 \%$ and $48.2 \%$ of the cases in each respective age group (Table 2). Among DEC, EAEC had a high proportion accounting for $51.6 \%$ (19 cases) of all DEC followed by ETEC $6.1 \%$ (11), EPEC 2.8\% (5) then EIEC 1.1\% (2). No EHEC were detected by the current study.

Table 1. Comparison of percentage positive samples by conventional culture versus PCR results

\begin{tabular}{|l|l|c|l|}
\hline Bacterial type & Conventional stool culture & PCR & $\begin{array}{l}\text { p-value } \\
0.05\end{array}$ \\
\hline DEC & $20 \%$ & $21.6 \%$ & $<0.05$ \\
\hline Shigella & $14 \%$ & $16.1 \%$ & $<0.05$ \\
\hline Salmonella & $4 \%$ & $5 \%$ & $>0.05$ \\
\hline Vibrio & $3 \%$ & $3.3 \%$ & $>0.05$ \\
\hline Campylobacter & $2 \%$ & $1.7 \%$ & $>0.05$ \\
\hline TOTAL & $42 \%$ & $47.7 \%$ & $<0.05$ \\
\hline
\end{tabular}


Table 2. Distribution of diarrheagenic bacteria isolated among cases and the controls (The bolded ones are statistically significant) by Chi square

\begin{tabular}{|l|l|l|l|l|}
\hline \multirow{2}{*}{ Pathogen } & \multicolumn{2}{|l|}{ Percentage of bacteria characterized) } & $\begin{array}{l}\text { Odds ratio } \\
\text { 95\% CI }\end{array}$ & P-value 0.05 \\
\cline { 2 - 5 } & Cases $(\mathrm{n}=180)$ & Control $(\mathrm{n}=180)$ & $3.3(1.6-13.0)$ & 0.006 \\
\hline DEC & $21.6 \%$ & $6 \%$ & $5.8(0.4-16.8)$ & 0.04 \\
\hline EAEC & $11.6 \%$ & $2 \%$ & 2.8 & 0.06 \\
\hline ETEC & $2.8 \%$ & $1 \%$ & $2.1(0.4-16.8)$ & 0.05 \\
\hline EIEC & $6.1 \%$ & $3 \%$ & $1.1(0.7-10.4)$ & 0.051 \\
\hline Shigella & $1.1 \%$ & $0 \%$ & $2.3(1.8-10.8)$ & 0.005 \\
\hline Salmonella & $16.1 \%$ & $7 \%$ & $2.5(0.1-14.6)$ & 0.061 \\
\hline Vibrio & $3.3 \%$ & $2 \%$ & $3.3(0.1-1.4)$ & 0.07 \\
\hline Campylobacter & $1.7 \%$ & $0 \%$ & $1.7(0.1-1.0)$ & 0.074 \\
\hline
\end{tabular}

Table 3. Percentage distribution of diarrheagenic bacteria among different Under five age groups.

\begin{tabular}{|l|l|l|l|l|l|l|}
\hline Age group (months) & E. coli & Shigella spp. & Salmonella spp. & Vibrio spp. & Campylobacter & Total \\
\hline $0-5$ & 4 & 1 & 0 & 0 & 0 & 5 \\
\hline $6-11$ & 7 & 2 & 0 & 0.3 & 1.7 & 11 \\
\hline $12-23$ & 6 & 5.1 & 2 & 2 & 0 & 15.1 \\
\hline $24-60$ & 4.6 & 8 & 3 & 1 & 0 & 16.6 \\
\hline TOTAL & 21.6 & 16.1 & 5 & 3.3 & 1.7 & 47.7 \\
\hline
\end{tabular}

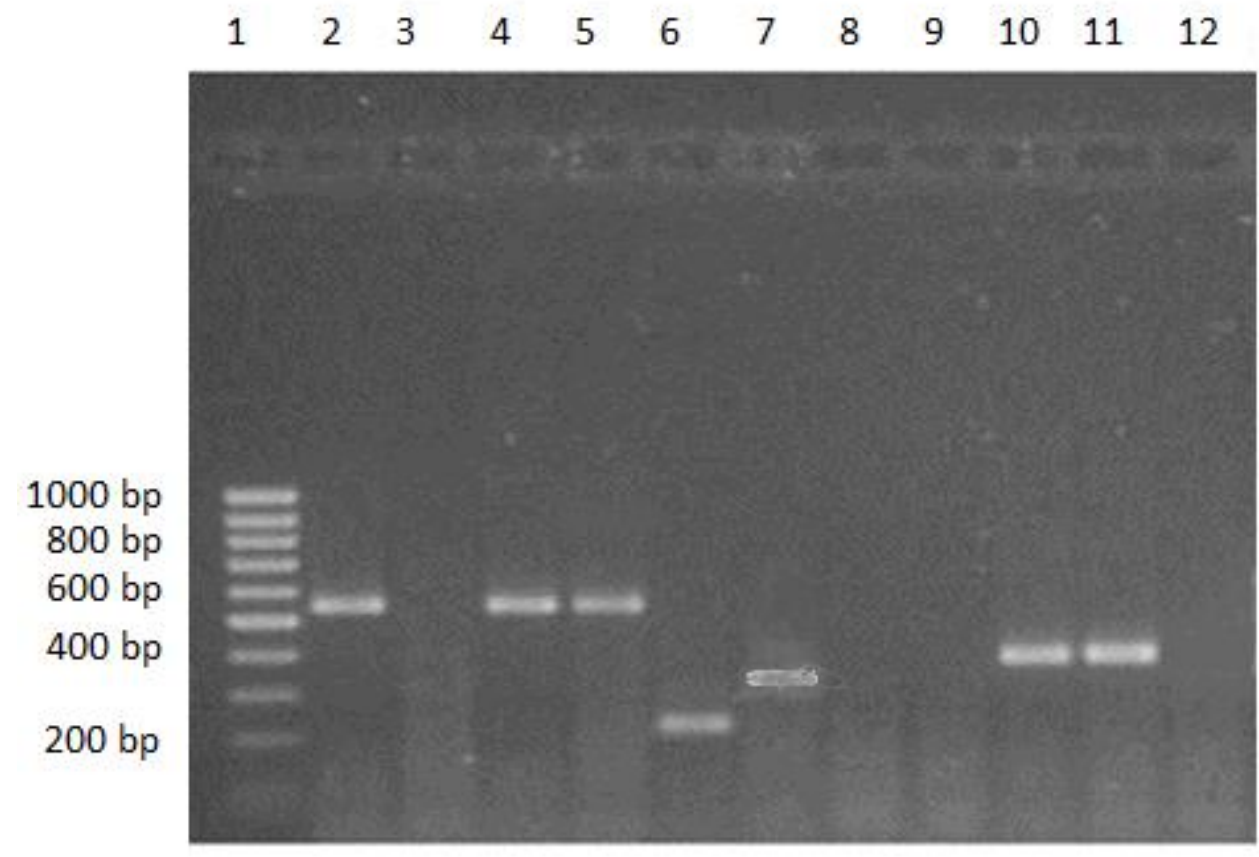

Figure 1. Agarose gel showing the PCR products obtained for the genes amplified by a three sample multiplex PCR reaction. 
Lane 1, 100-bp ladder DNA marker; lane 2,4,5, eae gene positive samples; lanes 3, 8, 9 negative samples; lane 6, LT gene positive sample; lane 7, bfpA gene positive sample; lanes 10- 11, ST gene positive sample and lane 12, negative control.

\section{Discussion}

In Dar Es Salaam City there is a rapid increase in population size in recent years. On average 25-30 under-five children attend each hospital per day due to diarrhea and at least 12-15 children are admitted/ hospitalized due to either acute severe diarrhea or severe dehydration that needs rehydration by intravenous infusions and other medical care.

Results of this study detected enteric pathogens in $67.7 \%$ of the cases and in $20 \%$ of the controls. The pathogens most strongly associated with diarrhea disease were diarrheagenic Escherichia coli (21.6\% of cases, 6\% of controls), Shigella spp. (16.1\% of cases, 5\% of controls) and Salmonellae, (10.6\% of cases, $3 \%$ of controls). The bacteria were mostly from children aging from 24 months and above.

Diarrheagenic Escherichia coli are the most frequently detected in cases of diarrhea and enterotoxigenic E. coli (ETEC) is one of the most important cause of childhood diarrhea in developing countries, though other diarrheagenic E. coli pathotypes are important too. The proportion of diarrheagenic $E$. coli identified from samples collected are in agreement with a previous study among children at Ifakara, Tanzania in which EAEC accounted for $63 \%$ of the diarrheagenic E. coli (Vargas et al., 2004) and in Dar Es Salaam (Moyo et al., 2007) in which entero-aggregative E. coli accounted for $64.1 \%$ and with other studies in other developing countries (Okeke et al., 2000; Sarantuya et al., 2004). Collectively, these studies seem to suggest the predominance of diarrhoeagenic E. coli and Shigella in causing childhood diarrhea in developing countries. It is worth noting also that, the proportion of entero-aggregative E. coli among children aged less than eleven months is significantly higher than in older children ( $\mathrm{p}<0.05)$, which is in agreement with the finding of Moyo et al., (2007). The prevalence of Salmonella species found in ninety samples (5\%) in this study falls within the reported range of $1-5 \%$ of gastroenteritis cases in most developing countries (WHO, 2001) and the serotypes were mainly S. Enteritidis (28.6\%) and S. Typhimurium $(57.1 \%)$. However, age differences were noted when comparing the present finding from other countries, with a higher prevalence of entero-aggregative Escherichia coli in infants aged less than six months (Okeke et al., 2000; Sarantuya et al., 2004; Prestrl et al., 1993, Kosek, et al., 2003).

Other diarrheagenic bacteria that were isolated and characterized included Vibrio chorelae in sixty samples $(3.3 \%)$ and campylobacter jejuni in thirty samples $(1.7 \%)$. On the other hand pathogens were detected in three hundred sixty stool samples $(20 \%)$ of the normal controls. These asymptomatic infections are common and may have arisen due to tolerance-inducing immune mechanisms, intra-species variation in virulence, or prolonged excretion of organisms after a diarrheal illness. 170 cases $(9.5 \%)$ were infected with more than one enteric pathogen. Yersinia enterocolitica were not isolated from any of stool samples in this current study. 
To date in Tanzania hospitals, the culture method has remained to be the 'golden standard' for the identification of the etiologic agents of diarrhea from stool specimens. The conventional culture has been modified in terms of chemical identification by introduction of an API (application profiling index) which combines all chemicals in a single test strip and results are read at one time, (figure 2.1). However, application of analytical profile index is not affordable by the majority of Tanzanians.

Attempts for directidentifications of diarrheagenic bacteria in stool specimen were developed using PCR-based methods (Logan et al., 2001, Persson and Olsen, 2005), though most of these methods can identify one pathogen and its close relatives, at a time. For the identification of multiple pathogens simultaneously the optimal PCR conditions for each pathogen-specific primer set is needed. To resolve this problem, a rapid multiplex PCR method which is very sensitive and specific, was developed that identifies several diarrhoeagenic bacteria in stool specimens using the same PCR conditions.

Results of this study showed 230 samples to be PCR positive but culture negative, this may be the result of non-culturable states of organisms in selective media, including dead and damaged bacterial cells. The results, which reveal a significant proportion of PCR-positive but culture-negative specimens were consistent with many other studies (Logan, et al. 2001, Gentry-Weeks, et al. 2002, Kulkarni, et al. 2002). Taken together with the epidemiological data presented in the present study, supported the view that PCR-based testing is more sensitive than conventional culture for the detection of enteric bacterial pathogens in stool samples. Two cases that were PCR-negative but culture-positive for campylobacter jejuni might be attributed to sequence diversity among $C$. jejuni isolates.

In the present study, it was shown also that a rapid and affordable PCR-based method (Multiplex polymerase chain reaction (mPCR)) may routinely be used in hospitals for the identification of the most common bacteria associated with diarrhea in developing countries, including the six pathotypes of $E$. coli and the five most common non- $E$ coli enteropathogens, Shigella species, Salmonella species, Y. enterocolitica, S. aureus, Campylobacter species and V. cholerae.

All E. coli strains tested in the assay were lactose fermenters according to culture and all non-E. coli isolates, except Campylobacter spp. were non-lactose fermenters. The assay was also capable of detecting atypical entero-pathogenic E. coli strains which carry the locus for E. coli effacement (LEE) but lack BFP which is in keeping with Moreno et al. (2008). These strains were recognized by the presence of the eae gene and the absence of the $b f p A$ gene. Such detection pattern was important as atypical EPEC strains were considered emerging pathogens in several developing countries as well as Europe, in keeping with other studies such as; Toma et al., (2003), Vidal et al., (2005), Wani et al. (2006), Alikhani et al. (2006), Moreno et al. (2008).

Facts on multiplex PCR for use in Tanzania: Previous reports on multiplex PCR assays have concentrated on identification of E. coli pathotypes (Matar et al. 2002, Nguyen et al. 2005, Brandal et al. 2007). However, the PCR methodology was modified to a three-sample reaction in order to increase the specificity and sensitivity of the reaction. MPCR is specific 
as multiple PCR primers were specific for each target, and no cross-reactivity was detected with heterologous DNA and validation of this PCR method confirmed that approximately 100 strains previously characterized were correctly identified by the three-sample PCR method, this is in keeping with other studies (Watterworth et al. 2005, Oscar et al., 2009). mPCR identification is rapid, as in 4 hours it is possible to isolate crude DNA preparations from a bacteria suspension, amplify the DNA, separate the DNA fragments in an agarose gel, and have a visual report of the banding pattern.

The mPCR assays have been simplified to facilitate the use in limited settings as stated by Oscar et al., (2009). When testing pure bacteria isolates, the assay can use crude DNA preparations rather than purified genomic DNA. The assay is also flexible with respect to the number of primer pairs and type of pathogens to identify. Furthermore, the assay may potentially identify enteropathogens from environmental sources, clinical isolates, or stool samples.

The minimal requirements for the assay's implementation include access to electricity, water, and refrigeration $\left(-10\right.$ to $\left.4{ }^{\circ} \mathrm{C}\right)$. These conditions are met in most hospitals and reference laboratories in Tanzania.

\section{Recommendations}

Treatment should not rely on microscopic examination of stool alone. The incorporation of many new technologies into the diagnostic laboratory will provide better epidemiological data and greater understanding of the public health problems and measures to control diarrheal disease.

Since gastrointestinal infections are very common in Tanzania with high associated mortality rate in infants and young children, public health prevention through fostering good hygiene and providing sanitary water and food supplies should be of the at most importance.

Future studies should focus on determining the antimicrobial susceptibility profile of diarrhoeagenic bacteria in children to avoid the use of common drugs that some pathogens may have became resistant to.

The combined effort of policy makers, research scientists, clinicians and administrators will help in management and control of this killer disease in Tanzania.

\section{Acknowledgement}

The authors would like to thank the Ifakara Health Institute for sponsoring the study and appreciate the technical assistance of all the staffs of the Muhimbili Central Pathology Laboratory under the supervision of Dr. Mabula Kasubi for their assistance in stool culture and microscopy.

\section{References}

Alikhani MY, Mirsalehian A, \& Aslani MM. (2006). Detection of typical and atypical enteropathogenic Escherichia coli (EPEC) in Iranian children with and without diarrhoea. Journal of Medical Microbiology, 55, 1159-1163. http://dx.doi.org/10.1099/jmm.0.46539-0 
Boom R, et al. (1990). Rapid and simple method for purification of nucleic acids. Journal of Clinical Microbiology, 28, 495-503.

Boschi-Pinto C, Velebit L, \& Shibuya K. (2008). Estimsting child mortality due to diarrhoea in developing countries. Bull World Health Organ. 86, 710. http://dx.doi.org/10.2471/BLT.07.050054

Brandal LT, et al. (2007). Octaplex PCR and fluorescence-based capillary electrophoresis for identification of human diarrheagenic Escherichia coli and Shigella spp. Journal of Microbiology Methods, 68, 331-341. http://dx.doi.org/10.1016/j.mimet.2006.09.013

Bryce J, et al. (2005). WHO estimates of the cause of death in children. Lancet. 365, 1147. http://dx.doi.org/10.1016/S0140-6736(05)71877-8

Gascon J, et al. (2000). Diarrhoea in children under 5 years of age from Ifakara, Tanzania: a case-control study. Journal of Clinical Microbiology, 38(12), 4459-4462. https:jcm.asm.org.

Gentry-Weeks, C., et al. (2002). Identification of two phylogenetically related organisms from feces by PCR for detection of Salmonella spp. Journal of Clinical Microbiology, 40, 1487-1492. http://dx.doi.org/10.1128/JCM.40.4.1487-1492.2002

Ghasemi AA. et al. (2013). Knowledge of Mothers in Management of Diarrhea in Under-Five Children, in Kashan, Iran. Nursing and Midwifery Studies. 1(3), 158-62. http://dx.doi.org/10.5812/nms.10393

Jafari F, et al. (2009). Diagnosis and prevalence of enteropathogenic bacteria in children less than 5 years of age with acute diarrhea in Tehran children's hospitals. Journal of infectious diseases, 21-27. http://dx.doi.org/10.1016/j.jinf.2008.10.013

Kosek M, Bern C., \& Guerrant RL. (2003). The global burden of diarrhoeal disease, as estimated from studies published between 1992- 2000. The Bulletin World Health Organization, 81(3), 197.

Kotloff KL, et al. (2013). Burden and aetiology of diarrhoeal disease in infants and younger children in developing countries (The Global Enteric Multicenter Study, GEMS): A prospective, case-control study. Lancet.382:209. http://dx.doi.org/10.1016/S0140-6736(13)60844-2

Kulkarni SP, et al. (2002). Detection of campylobacter species: a comparison of culture and polymerase chain reaction based methods. Journal of Clinical Pathology, 55, 749-753. http://dx.doi.org/10.1136/jcp.55.10.749

Logan JM, et al. (2001). Rapid identification of Campylobacter spp.by melting peak analysis of biprobes in real-time PCR. Journal of Clinical Microbiology, 39, 2227-2232. http://dx.doi.org/10.1128/JCM.39.6.2227-2232.2001

Mashoto, K.O., et al. (2014). Prevalence, one week incidence and knowledge on causes of diarrhea: household survey of under-fives and adults in Mkuranga district, Tanzania. BMC Public Health, 14, 985. http://dx.doi.org/10.1186/1471-2458-14-985 
Matar GM., et al. (2002). The multiplex-PCR-based detection and genotyping of diarrhoeagenic Escherichia coli in diarrhoeal stools. Ann Tropical Medical Parasitology, 96, 317-324. http://dx.doi.org/10.1179/000349802125001032

Mengiste B, Berhane Y, \& Worku A. (2013). Prevalence of diarrhea \& associated risk factors among children under-five years of age in Eastern Ethiopia: A cross-sectional study. Open Journal of Preventive Medicine. 3(7), 446-453. http://dx.doi.org/ 10.4236/ojpm.2013.37060.

Mhalu FS, et al. (1988). Prevalence of infection with rotavirus and enteric adenoviruses among children in Tanzania. NIPH Ann, 11(1), 3-7.

Ministry of health and social welfare, Tanzania. (2008). Country health profile.

Moreno AC, et al. (2008). Etiology of childhood diarrhea in the northeast of Brazil: significant emergent diarrheal pathogens. Diagnostic Microbiology of Infectious Diseases. In press.

Moyo Sabrina J, et al. (2011). Age specific aetiological agents of diarrhoea in hospitalized children aged less than five years in Dar es Salaam, Tanzania. BMC Pediatrics, 11, 19. http://dx.doi.org/10.1186/1471-2431-11-19

Moyo Sabrina J, et al. (2007). Prevalence of enteropathogenic viruses and molecular characterization of group A rotavirus among children with diarrhea in Dar es Salaam Tanzania. BMC Public health. 7,359. http://dx.doi.org/10.1186/1471-2458-7-359

Moyo Sabrina J, et al. (2007), Identification of diarrheagenic E. coli isolated from infants \& children in Dar es Salaam, Tanzania. BMC Infectious diseases. http://dx.doi.org/10.1186/1471-2334-7-92

Mwambete KD \& Joseph R.. (2010). Knowledge \& perception of mothers \& care-givers on childhood diarrhea \& its management in Temeke municipality, Tanzania. Tanzania Journal of Health $\quad$ Researches. $12(1), \quad$ 47-54. 20737828. http://dx.doi.org/10.4314/thrb.v12i1.56278

National Bureau of Statistics (NBS) Tanzania and Measure DHS+. November (2002). Tanzania Reproductive and Child Health Survey. Dar es Salaam, Tanzania: National Bureau of Statistics and Macro International.

Nguyen TV, et al. (2005). Detection and characterization of diarrheagenic Escherichia coli from young children in Hanoi, Vietnam. Journal of Clinical Microbiology, 43, 755-760. PMID: 15695676. http://dx.doi.org/10.1128/JCM.43.2.755-760.2005

Okeke IN, et al. (2000). Heterogeneous virulence of enteroaggregative Escherichia coli strains isolated from children in Southwest Nigeria. Journal of Infectious Diseases, 181(1), 252-260. http://dx.doi.org/10.1086/315204

Oscar G. Gómez-Duarte, Jing Bai, \& Newel E. (2009). Detection of E. coli, Salmonella spp., Shigella spp., Yersinia enterocolitica, Vibrio cholerae, and Campylobacter spp. enteropathogens by Three-reaction Multiplex PCR. Diagn. Microbiology of Infect. Diseases, 
63(1), 1-9. http://dx.doi.org/10.1016/j.diagmicrobio.2008.09.006

Parashar U, et al. (2003). The global burden of diarrhoeal disease in children. Bulletin of the World Health Organization, 81(4), 236.

Park YS, Lee SR \& Kim YG. (2006). Detection of Escherichia coli O157:H7, Salmonella spp., Staphylococcus aureus and Listeria monocytogenes in kimchi by multiplex polymerase chain reaction (mPCR). Journal of Microbiology. 44, 92-97.

Persson S \& Olsen KE. (2005). Multiplex PCR for identification of Campylobacter coli and Campylobacter jejuni from pure cultures and directly on stool samples. Journal of Medical Microbiology, 54, 1043-1047. http://dx.doi.org/10.1099/jmm.0.46203-0

Presterl E, et al. (2003). Frequency and virulence properties of diarrheagenic Escherichia coli in children with diarrhea in Gabon. American Journal of Tropical Medicine and Hygiene, 69(4), 406-410.

Rappelli P, et al. (2005). Pathogenic enteric Escherichia coli in children with and without diarrhea in Maputo, Mozambique. FEMS Immunology and Medical Microbiology, 43, 67-72. http://dx.doi.org/10.1016/j.femsim.2004.07.006

Reither K, et al. (2007). Acute childhood diarrhoea in northern Ghana: epidemiological, clinical and microbiological characteristics. BMC Infectious Diseases, 7, 104. http://dx.doi.org/10.1186/1471-2334-7-104

Research and Analysis Working Group (R\&AWG). (2002). Poverty and Human Development Report (PHDR). Dar es Salaam: R\&AWG.

Research on Poverty Alleviation (REPOA). October (2003). Policy and Service Satisfaction Survey. Main results.Working Draft.

Sarantuya J, et al. (2004). Typical enteroaggregative Escherichia coli are the most prevalent pathotype among E. coli strains causing diarrhea in Mongolian children. Journal of Clinical Microbiology, 42(1), 133-139. http://dx.doi.org/10.1128/JCM.42.1.133-139.2004

Toma C, et al. (2003). Multiplex PCR assay for identification of human diarrheagenic Escherichia coli. Journal of Clininical Microbiology, 41, 2669-2671. http://dx.doi.org/10.1128/JCM.41.6.2669-2671.2003

UNICEF. (2008). Annual health bulletin. Vol 13.

Vargas M, et al. (2004). Etiology of diarrhea in children less than five years of age in Ifakara, Tanzania. American Journal of Tropical Medicine 70 (5): 536-539.

Vidal M, et al. (2005). Single multiplex PCR assay to identify simultaneously the six categories of diarrheagenic Escherichia coli associated with enteric infections. Journal of Clinical Microbiology, 43, 5362-5365. http://dx.doi.org/10.1128/JCM.43.10.5362-5365.2005

Wani SA, et al. (2006). Investigation of diarrhoeic faecal samples for enterotoxigenic, Shiga toxin-producing and typical or atypical enteropathogenic Escherichia coli in Kashmir, India. 


\section{Macrothink}

FEMS Microbiology Letter, 261, 238-44. http://dx.doi.org/10.1111/j.1574-6968.2006.00354.x

Watterworth L, et al. (2005). Multiplex PCR-DNA probe assay for the detection of pathogenic Escherichia coli. Journal of Microbiological Methods, 60, 93-105. http://dx.doi.org/10.1016/j.mimet.2004.08.016

World Health Organization, (2014). World health report, Geneva, Swiss.

World Health Organization, (2013). World health report, Geneva, Swiss.

World Health Organization, (2007). World health report, Geneva, Swiss.

World Health Organization. (2005). The world health report 2005-Make every mother and child count. WHO Press. Geneva, Switzerland.

World Health Organization, (2001). IMCI Integrated Mangagement of Childhood Illness. Model Chapter for Textbooks. Document no WHO/FCH/CAH/00.40 Geneva, Switzerland.

\section{Copyright Disclaimer}

Copyright for this article is retained by the author(s), with first publication rights granted to the journal.

This is an open-access article distributed under the terms and conditions of the Creative Commons Attribution license (http://creativecommons.org/licenses/by/3.0/). 